\title{
FLÜT VIBRATOSUNUN TEKNIK, MÜZIKAL VE KÜLTÜREL BOYUTU
}

\author{
Halit TURGAY*1 \\ *Mersin Üniversitesi Devlet Konservatuvarı
}

\begin{abstract}
Özet
Vibrato kavramı üzerinde yüzyıllardır devam eden tartışmalar hâlâ güncelliğini korumaktadır. Her flüt ekolünün hatta aynı ekolün temsilcilerinin farklı söylemleri, çalışmaları ve uygulamaları vardır. Bu farklı öğretiler kaotik bir ortam yaratmaktadır. Vibrato kullanımı, ulusal veya uluslararası platformda yarışmalara katılan, orkestra seçmelerine giren genç flütistlerin sıklıkla eleştirildikleri temel unsurlardan biri haline gelmiştir. Farklı uygulama yöntemleri ile sınıflandırılan vibrato kullanımı, sanatsal açıdan değil, genelde teknik bir konu olarak değerlendirilmeye başlanmıştır. Aslında estetik bir kavram olarak değerlendirilmesi gereken vibrato kullanımı kişinin ruhu ile bütünlük içerisinde olmalıdır.
\end{abstract}

$\mathrm{Bu}$ makalede, vibratonun ve flüt vibratosunun tarihsel süreci araştırımış ve geçmiş söylemlere, çalışmalara ve uygulamalara örnekler verilmiştir. Bununla beraber vibratonun sadece süsleme sanatı, teknik ve müzikal bir olgu olmasının dışında, bir kültür, sanatsal bir etken ve felsefi bir boyutu olduğundan bahsedilmiştir.

Anahtar kelimeler: Vibrato, Flüt, Flüt vibratosu.

THE CULTURAL, MUSICAL AND TECHNICAL EXTENT OF FLUTE VIBRATO

\begin{abstract}
Debates about the concept of vibrato on-going for centuries still remain to be up-to-date. Each flute school, even the representatives of same school, has their own different discourses, studies and practices. These various doctrines create a chaotic atmosphere. The use of vibrato has become one of the main elements that young flutists who compete in national or international platforms, attend orchestra selections have frequently been criticised. The use of vibrato classified with different practice methods has begun to be considered as a technical issue, not as an artistic one. The use of vibrato that should mainly be considered as an aesthetic concept has to be in integrity with the person's spirit.

In this article, the historical process of vibrato and flute vibrato has been explored and examples have been referred to past discourses, studies and practices. Besides, it has been mentioned that vibrato is an artistic element and has a philosophical extent as well as the fact that it is also a decorative art, technical and musical fact.
\end{abstract}

Keywords: Vibrato, Flute, Vibrato on flute.

\section{Giriş}

Vibrato müziğin nabzı ve sesin ruhudur. İnsanoğlu var olduğundan beri vibrato da var olmuştur. Insanların veya hayvanların korku, heyecan, kaygı gibi farklı psikolojik ortamlarda bulunmaları seslerindeki titreşimi değiştirmektedir. Bu nedenle vibratonun en ilkel hali bugünkü vibratonun gelişiminde büyük bir etken olmuştur. Vibratonun müzik tarihindeki yolculuğu, ilk yazılı kaynakların gün ışığına çıkmasıyla birlikte önem kazanmıştır. Başlangıçta telli çalgılar tarafından bir efekt olarak

\footnotetext{
${ }^{1}$ Yazışma yapılacak yazar: halitflute@gmail.com
} 
kullanılmıştır. Zamanla farklı yöntemler kullanılarak müziğin estetik boyutunun derinleştirilebilmesi için bir süsleme sanatı olarak kabul edilmiş ve müzikal ifadenin vazgeçilmez bir parçası haline gelmiştir.

Vibrato ifadeli bir çalış için, sesin akordunu değiştirmeden, sesin içinde meydana gelen ses dalgalarının varyasyonlarıdır. Tarihsel süreç içerisinde bu varyasyonlara sanatsal boyut kazandırabilmek için farklı yaklaşımlar ve çalışma teknikleri üretilmiştir. Aslında tümüyle insan ruhu ve psikolojisiyle bütünleşen bu olgu, bilinen çalışma yöntemlerinin ve önerilerinin dışında teknik, psikolojik ve ruhani bir boyut içermektedir. Bunu kültürel boyuta taşıyabilmek için yüzyıllardır uygulanan yöntemleri, yaklaşımları ve çalışma tekniklerini bilmek en önemli ayrıntıdır. Vibrato her ne kadar sistematik çalışmalarla geliştirilebilen bir teknik ayrıntı gibi görünse de, aslında müziğin özünde var olan en önemli konu başlığıdır. Bu bağlamda kültürel birikim, sanatçının yorumuna entelektüel anlamda farklı bir boyut katacaktır. Flüt vibratosu hakkında yazılmış ilk pedagojik bilgiler 1707 yılında Fransa'da ortaya çıkmıştır. Başlangıçta yaylı çalgılar örnek alınmış ancak nasıl uygulanacağı konusunda çok farklı görüşler ortaya çıkmış ve bu farklı görüşler kaotik bir ortam yaratmıştır.

Flütün teknolojik gelişimi doğrultusunda tonun vazgeçilmez bir parçası haline gelen vibrato, eğitim sistemi içerisinde önemli bir rol üstlenmiştir. Bu rol zamanla teknik ve pedagojik anlamda da geliştirilmiştir. Fiziksel açıdan mükemmel bir nefes tekniği ve kas kontrolü gerektiren bu yeni anlayış çalgı tekniğine yeni bir disiplin kazandırmıştır. Günümüzde flüt vibratosu bir uzmanlık alanı olarak görülmektedir. Çalınan eserin dönemlerine göre farklı yaklaşımlar gösterilerek eserler stilize edilmektedir. Bu durum flütisti, vibratonun tarihsel süreç içerisinde göstermiş olduğu gelişimi anlamak ve irdelemek zorunda bırakmıştır. Gerek günümüzdeki flüt yarışmaları, gerekse orkestra seçmelerinde çalınan eserler arasındaki stil farkı ve bu stil farkının yansıtılıp, yansıtılamadığı direkt olarak müzisyenin kültürel birikimiyle bağdaştırımaktadır. Bununla beraber Çağdaş bestecilerin eski dönemlerden beri uygulanan yöntemler ışığında, hangi notaya ne kadar vibrato yapılması gerektiğini belirtmeleri, flütistin açık bir şekilde vibratonun hızının kontrol edilebilir bir faktör olduğunu düşünmek zorunda bırakmıştır.Tüm bu gelişmelere, çalışmalara ve bilimsel yaklaşımlara karşın vibratonun nasıl yapılması ve kullanılması gerektiği hakkındaki tartışmalar halen devam etmektedir.

\section{Flüt Vibratosunun Tarihsel Süreci}

Tarihsel süreçte vibrato, Latincede, "crispatio, reverberatio, treidatio", İtalyancada, "ondeggiamento, tremolo, tremulo, tremar, trillo, vibrato", Ingilizcede "fireworks, close shake, shake, quiver, sting, undulation", Fransızcada "balancement, battement, chevroment, flatté, flattement", Almancada "beben, bebung, klophen" gibi kelimelerle tanımlanmıştır (Gartner,1981:35).

Türkçede vibrato olarak kullandığımız kelimenin karşılığı, "titreşim, salınım daha duygulu ve güzel anlatım amacıyla, sesin çok hafif ancak düzenli, çok sık ve hızı salınımıyla, titretilmesiyle oluşan, çok az frekans farklılıkları nedeniyle çıkan ses anlamındadır" (Aktüze, 2003:640).

Müzikal ifadenin en zarif ve anlamlı ögelerinden biri olan vibrato, hiç kuşkusuz günümüzün bir keşfi değildir. Vibrato tekniği, hem yaylı çalgılarda, hem de üflemeli çalgılarda günümüze kadar değişim göstermiş, farklı uygulama teknikleri ve çalışma yöntemleri ile geliştirilmiştir.

Vibratonun nota üzerinde yazılı olarak gösterildiği ilk uygulamaya, M.Ö. 350 yıllarında Yunan telli çalgısı Kitara çalma sanatı hakkında yazıımış bilimsel bir metotta rastlanmıştır. O dönemde bu uygulama, çalgının telleri üzerinde mızrapın ileri-geri hareketi ile yapılıyordu. Aristoxenus² (M.Ö. 360- M.Ö. 300) ve onun takipçileri tarafından el yazması olarak kaleme alınmış bu bilimsel metodun çok azı günümüze ulaşmıştır. Ancak Johann Gottfried Heinrich Bellermann"'ın (1832-1903), 1873'te "Armoninin Temel Esasları Olarak Müzikal Aralıkların Boyutu" (Die Grösse der musikalischen Intervalle als Grundlage der Harmonie) adlı kitabında derlemeleri toplayarak yayınlaması üzerine, Robert Haas ${ }^{4}$ (1886-1960), tüm bu çalışmaları inceleyerek bu mızrap hareketlerini vibratoya benzer bir efekt olarak tanımlamıştır (Gartner, 1981:16).

Ortaçağın gelmesiyle ilk kez M.S. X. Yüzyılda yazılmış ve günümüze kadar ulaşan çok sayıda yazılı doküman üzerinde staccato* veya ses vibratosunu belirten yazılı sembollere rastlanmıştır. Bunların "bistropha ve tristropha" gibi işaretlerle ritmik ve tonal süslemeleri gösteren müzikal dekoratif süslemeler

\footnotetext{
${ }^{2}$ Yunan gezgin filozof.

${ }^{3}$ Alman müzik teorisyeni ve besteci.

${ }^{4}$ Avusturyalı müzikolog.

* İtalyanca staccato: Sesi kesik kesik duyurmak. (Aktüze,2003:554)
} 
(decorative neume) olduğu düşünülmektedir. Ortaçağın sonlarına doğru Latin yazarlar, müzikal süslemeleri açıklayabilmek için farklı semboller kullanmışlardır. Bunların arasında bir çeşit trili tanımlayan "crispatio", "trepidatio" ve vurgu anlamına gelen "reverberatio" yer almaktadır (Gartner,1981:16).

Bu çağda ilk müzik eserlerinin yazılmasıyla birlikte, vibrato anlayışını sembolize eden işaretler müzikal ifadenin derinleştirilmesini sağlamak amacıyla temelde müziğe estetik bir anlayış katmak için kullanılmıştır.

Vibratonun teknik anlamda nasıl uygulanacağıyla ilgili ilk pedagojik düşünceler Martin Agricola ${ }^{5}$ (14861556) ile ortaya çıkmıştır. Agricola, üflemeli çalgı çalanlara vibratoyu daha iyi anlaması ve öğrenmesi için ses eğitimi almayı önermektedir. Bu düşünce günümüzde de geçerliliğini yitirmemiştir. Flüt vibratosundan akademik olarak ilk kez XVIII. Yüzyılda bahsedilmiş ve bu dönemin önemli müzisyenleri vibrato ile ilgili gözlemler ve araştırmalar yapmıştır. Fransız flütist ve besteci Jacques-Martin Hottetere (1674-1763), Alman flütist ve pedagog Johann Joachim Quantz (1697-1773), Alman besteci Carl Philippe Emmanuel Bach (1685-1750) kemancı, şef, besteci ve pedagog Leopold Mozart (1719-1787), sadece yorumcu ve besteci olarak ün kazanmamışlar, aynı zamanda kendi dönemlerinden çok sonra etkilerini gösteren müzikal formasyon çalışmalarıyla da tanınmışlardır. Tarihteki müzikal çalışmaları ve yaşamı yansıtan son derece değerli olan bu eserler, vibratonun gelişmesine önemli katkılar sağlamıştır (Ersöz, 2014: 2).

Hottetere'nin 1707 yılında yazdığı Barok Flüt, Blok Flüt ve Obua'nın Temel Kuralları (Principes de la Flute Traversiere, de la Flute a Bec, et du Hout-bois) adlı metodunda, flüt vibratosu ayrıntılı bir şekilde ele alınmıştır. Hottetere metodun bir bölümünü vibratoyla ilgili olan "battement" ve "flattement" adlı iki süslemeye ayırmıştır. Battement, yaylı çalgıların Barok ${ }^{*}$ dönemde uyguladıkları trilden ve mordandan farklı olarak yapılan vibratoya benzer bir çeşit süslemedir. Flüt üzerinde çalınan sesin hemen altındaki parmak deliğinin yarısı kapatılarak veya tamamı kapatılarak elde ediliyordu. Flattement ise dönemin üflemeli çalgılarının kullandığı bir terimdir ve çalınan notanın üstünden başlayarak elde edilen bugünkü vibratonun ilk uygulamasıdır (Gartner,1981:21).

1752'de Quantz, Flüt Çalmayı Öğrenme Üzerine Deneme (Versuch Einer Anweisung Die Flöte Tracersiere Zu Spielen) adlı metodunu yazmış ve bu metodu Büyük Frederick ${ }^{6}{ }^{\prime}$ adamıştır. Bu metotta, müzik pedagojisi üzerine geniş kapsamlı araştırmalar yapmış ve ortaya koyduğu müzikal öngörülerle flütün daha etkili, soylu, derin bir anlayışla çalınabileceğini belirtmiştir. Bu bağlamda vibrato ile ilgili açıklamalarda bulunmuştur. Quantz, göğüs hareketleri ile flüt tonunun geliştirilebileceğinden bahsetmiş ve bu hareketler neticesinde ortaya çıkan titreşimleri (vibrato) aşırı güç kullanmadan sakinlik içerisinde yapılmasını önermiştir. Ayrıca iyi bir flüt tonuna sahip olmak için dudaklarda elde edilmesi gereken esneklikten de söz etmiştir. Bu esnekliği dudakların ileri-geri çekilip itilmesi gereken hareketler olarak yorumlamıştır. Ancak vibratonun dudaklarının esnekliği ile mi, yoksa göğüs kafesinden alınan destek ile mi, uygulanacağı konusunda fikir ayrımında kalmıştır. Kendisinden çok daha önce tartışılmaya başlanan bu önemli konuyla ilgili, Quantz da kitabında daha fazla bilgiye yer vermemiş bunun yerine flüt tonunun geliştirilmesi konusuna odaklanmıştır. Bununla beraber İtalyanların Messa di voce olarak adlandırdıkları, yarım ölçü veya tam ölçü boyunca uzayan notalar üzerinde vibratoyu çağrıştıran flattement tekniğini tercih etmiştir (Gartner,1981:23). Ancak Quantz, Hottetere'nin flattement vibratosuna benzer bir vibratoyu kullanmasına rağmen bu yöntemin sesi pesleştireceği konusunda flütistlerin dikkatini çekmiştir. Bununla beraber ortaya çıkan pesliğin, dudak hareketleri ile üfleme pozisyonunda düzeltmeler yaparak telafi etmelerini önermiştir. Pedagojik anlamda nasıl uygulanabileceği konusunda kitabının "Adagio Yorumlama Stili" (Manner of Adagio) bölümünde, ağır ve melankolik** anlatım içeren cümlelerde, özellikle uzun notalar üzerinde kullanmayı önermiştir (Quantz, 1752: 165-166).

\footnotetext{
${ }^{5}$ Alman besteci, akademisyen ve müzik eleştirmeni.

* Tuhaf şaşırtıcı anlamına gelen ve deforme incileri tanımlamakta kullanılan Barocco sözcüğünden doğan, önce klasik ölçülerden uzaklaşan mimari tarz için, sonra da süsleme, sanat eserler, giyim ve mobilya için kullanılan terim, o çağın müziğine de uygulanmıştır (Aktüze, 2003:46).

${ }^{6}$ Prusya Kralı ve amatör flütist.

* İtalyanca Messa di voce: Fransızca; Son file, Sesin düzeltilmesi. XVIII. yüzyılda çok önemli olan, İtalyan (Bel canto) şark1 stilinde hafif (pianissimo) sesin giderek güçlenip yükselmesi (fortissimo), sonra yine eski haline dönmesi. Karşıtı: Filar la voce, Filar il tuano.

${ }^{* *}$ Cantabile, Arioso, Affettuoso, Andante, Andantino, Largo, Larghetto gibi bölümlerin müzikal ifade biçimi.
} 
1834'de dönemin virtüöz flütistlerinden Anton Bernhard Fürstenau (1792-1852), dönemin ünlü keman virtüözü Louis Spohr'un (1784-1859) birçok fikrini flüt vibratosu üzerinde uygulamıştır. Flüt Çalma Sanatı (Die Kunst Des Flötenspiel Op.138, 1. cilt) adlı metodunda 3 farklı vibrato stilinden bahsetmiştir. Birincisi değişken hava basıncı (Bebung'u' ${ }^{* * *}$ ), ikincisi alt çenenin titreme hareketi ve üçüncüsü parmak vibratosu olmuştur (Gartner,1981:32).

Fürsteanu, Bebung'u; doğallığıyla, dinleyicide heyecanı, tutkuyu, sürükleyici bir etkiyi açığa çıkaran insan sesindeki vibratonun bir taklidi şeklinde tasvir etmiş ve bunu flüt çalarken bir avantaj olarak kullanılabileceğini düşünmüştür. Bu yöntem akciğerlerdeki hava basıncının ani bir şekilde değiştirilmesi (en iyi ve en güvenli yoldur) veya çene hareketlerinin neden olduğu titreşimlerle elde edilir. Fürstenau, nefes vibratosunun en iyi uygulama yöntemi olduğunu belirtse de, teknik anlamda nasıl yapılacağı konusunu cevapsız bırakmıştır. Çene vibratosunun nefes vibratosunun yerini alabileceğini fakat bunun çok iyi öğretilmesi gerektiğini söylemiştir. Daha önce Quantz'ın dudakları ileri-geri çekerek vibrato elde etme yönteminden bahsettiği gibi Fürstenau da nefes vibratosu yerine çeneyi titreterek vibrato yapmanın alternatif olacağını düşünmüştür (Gartner,1981:33).

Bununla beraber Fürstenau, artistik ve estetik açıdan vibrato kullanımı hakkında detaylar vermiştir. "Bir çalgı, sadece bazı durumlarda insan sesinin çekiciliğine ve büyüsüne yaklaşabilir, bundan dolayı vibrato, insan sesinin yapay bir taklidi olmamalıdır. Eğer içtenlik, farkındalık ve derin duygularla birlikte kullanılıyorsa, vibrato yapmak uygundur. Duygu yüklü pasajlar çalınsa dahi her notaya vibrato yapmak anlamsızdır. Sadece duygunun en yoğun olduğu yerlerde kullanılmalıdır. Aksi takdirde, vibrato yapmak duygusal, ağlamaklı bir etki yaratır. Estetik açıdan vibratoyu bir nota üzerinde üç veya dört dalga ile sınırlamalı ve bu nota da müziğin tepe noktasından seçilmelidir. Fürstenau'nun kendi yazdığı eserlerde vibrato işareti notalar üzerinde dalgalanma sembolü ile gösterilmiştir. Genelde bu sembolleri uzun sesler, fermatalı* notalar, tercihen flütün 3 . oktavındaki seslerde ve özellikle pianodan ${ }^{* *}-$ forteye $^{* * *}$ yükselen (crescendo), forteden-pianoya alçalan (decrescendo) pasajlarda kullanmıştır (Gartner, 1981:33).

Alman flüt yapımcısı, besteci ve flütist Johann George Tromlitz'in (1730-1805), "Flüt Çalmak için Ayrıntılı ve Genişletilmiş Dersler" (Ausführlicher Und Gründlicher Unterricht Die Flöte Zu Spielen) adlı metodunda, nefesle elde edilen vibratonun seste uğuldamayı andıran kötü bir etki bıraktığını söylemiştir. Ayrıca bu şekilde vibrato yapmanın göğüs kafesinde olumsuz etkiler yaratmasından dolayı sesin dengesini, sağlamlığını ve temizliğini olumsuz yönde etkileyeceğini yazmıştır. $O$ dönemde Tromlitz, Quantz'ın vibrato hakkında yaptığı çalışmaları geliştirmesi sebebiyle bir teorisyen ve mucit olarak da tanınmıştır. Metodunda özellikle Hottetere'nin flattement'ini andıran bir tür parmak vibratosu kullanmayı önermiştir. Tromlitz genelde daha düz bir flüt tonunu tercih etmiş ve vibratoyu sürekli kullanmak yerine, belirli yerlerde kullanarak etkisini ve niteliğini arttırmıştır. Ayrıca Barok flütün kısıtı parmak pozisyonlarından dolayı her notada flattement elde etmenin zorluğunu vurgulamıştır. Pedagojik anlamda vibratonun, fermata ve kadans girişlerinde kullanılmasını önermiştir (Gartner,1981:27-28).

1847'de Alman flütist ve enstrüman yapımcısı Theobald Boehm (1794-1881) tarafından anahtar sistemi geliştirilmiş olan "Boehm Sistem"* metal flütün kullanılmaya başlanmasıyla birlikte, flüt çalım tekniğinde ve eğitiminde büyük bir devrim yaşanmıştır. Bu devrimi ilk olarak kabul eden ve eğitimin sistemi içerisinde yer veren modern Fransız Flüt Okulu*'dur. Önderliğini Joseph Henri Altés ${ }^{7}$ ve Louis

\footnotetext{
*** Almanca Bebung: Sarsılmak, titremek kelimesinden klavsen ya da telli çalgılarda parmağın tuştaki ya da perdedeki basıncını azaltıp çoğaltarak yapılan vibrato (Aktüze,2003:53).

* İtalyanca Fermata: XV. Yüzyıldan beri notanın ya da susmanın üstüne veya altına belirsiz bir süre uyulmak için konulan durma, susuş işareti. Durak noktası (Aktüze,2003:191).

** İtalyanca Piano: Hafif, yumuşak sesle (Aktüze,2003:431).

*** İtalyanca Forte: Kuvvetli, güçlü (Aktüze,2003: 203).

* Ses delikleri 1831'de Theobald Böhm'ün tarzında, kolay çalışa göre değil, akustik prensiplerine göre açılmış ve Londra'da C. Nicholson tarafından geliştirilmiş $68 \mathrm{~cm}$ boyunda, orta ve tizlerde parlak sesli, çapraz flüt, Bu sistem obua, fagot ve klarnete de uygulanmıştır (Aktüze, 2003:230)

** XIX. Yüzyılın ortalarında kromatik sisteme sahip gümüşten yapılan Boehm Sistem flütün Paul Taffanel'in önderliğinde Fransızlar'ın vibrato kullanımında ton, teknik gibi konuları müziksel bir yaklaşımla orta koydukları anlayışın eğitimde yeni bir başlangıç noktası olarak kabul edilmesi.

${ }^{7}$ Fransız flütist, besteci, şef ve pedagog.
} 
Dorus ${ }^{8}$ 'nun yaptığı ve daha sonra Paul Taffanel9'in (1844-1908) desteklediği bu yeni oluşum, gelişen teknoloji ve flütün yapısal gelişimi doğrultusunda birçok yeni çalışma tekniğinin metodik anlamda temelini oluşturmaya başlamıştır. Öncelikle kromatik anahtar sisteminin silindirik ve metal bir tüp üzerinde yapılandırılması enstrümanın kolaylıkla çalınmasını sağlamıştır. Yenilenen anlayış çerçevesinde vibrato da tonun ayrılmaz bir parçası haline gelmiştir. Ancak o dönemde vibratonun nasıl elde edileceği teknik olarak öğretilmemiştir. Genelde bu terim şancılar örnek alınarak şarkılama anlayışı içerisinde müzikal ifadeyi ve duyguyu güçlendirmek anlamında kullanılmıştır. Yine de hava basıncı kullanarak elde edilmesi konusunda ortak bir görüş hâkim olmuştur. Ancak hiçbir zaman metodik bir çalışma ve yaklaşım ortaya çıkmamıştır.

Günümüzde İngiliz flütist Geoffrey Gilbert'in (1914-1989), Fransız Flüt Okulunu örnek alarak geliştirdiği İngiliz Flüt Okulunda, vibrato sistemli bir çalışma anlayışı kazanmıştır. Bu durum sadece bireysel bir yetenek olarak algılanmayıp, bilimsel ve metodik bir çalışma anlayışı çerçevesinde, standart flüt çalışma tekniklerine ait temel bir öğreti olarak da geliştirilmiştir. Bu modern vibrato çalışma tekniklerine ait örneklere, Angeleita S. Floyd'un ${ }^{10}$ "Gilbert'in Mirası" (The Gilbert Legacy) ve Trevor Wye ${ }^{11}$ 'In "Vibrato ve Entonasyon Çalışma Kitabı No.4" (Practice Book for the Flute Volume 4, Intonation and Vibrato) adlı kitaplarında rastlanmaktadır.

Vibrato direkt olarak tonun içerisinde etkin ve vazgeçilmez bir olgudur. Vibratonun hızını ve yoğunluğunu kontrol edebilmek için tümüyle karın kaslarının gelişimine bağlı olarak hava basıncı yöntemi ile kontrol sağlanmaktadır. Bu güncel yöntem, flüt tonu üzerindeki psikolojik renk değişimlerini çok daha doğal, akıcı ve akılcı elde etmemizi sağlamaktadır.

\section{Flüt Vibratosunun Kültürel Boyutu}

Müzikal yorum kişinin entelektüel birikimi ile doğru orantılıdır. Sürekli vibrato kullanımı, yorumu olumsuz etkiler. Ayrıca performans boyunca beraber çaldığı müzisyenleri olumsuz etkiler ve dinleyiciyi de irite eder. Bu durum sıkıcı bir müzikal atmosfer yaratır (Morris,1991:48). Vibrato kullanımında rafine bir müzikal ifadenin ve sanatsal olgunluğun elde edilebilmesi için öncelikle melodik diksiyon, ritmik diksiyon, armoni ve eser analizi konularının kavranması gerekmektedir. Bununla beraber, sanat tarihi, felsefe, edebiyat, mitoloji, psikoloji ve güzel sanatların tüm dallarıyla ilgilenmek ve birikim sahibi olmak kültürel boyutu oluşturur. Çaldığımız eserlerin bestecileri ve yapıları farklı dönemlere aittir. Örneğin, Johann Sebastian Bach ${ }^{12}$ (1685-1750) Barok dönem, Wolfgang Amadeus Mozart ${ }^{13}$ (1756-1791) Klasik dönem* ve Carl Reinecke ${ }^{14}$ (1824-1910) Romantik döneme ${ }^{* *}$ ait bestecilerdir. Bu dönemleri anlamak, irdelemek, sanatsal olayların akışını bilmek, sanat akımlarının birbirleri arasındaki etkileşimini öğrenmek birincil amacımız olmalıdır. Ayrıca bestecilerin etkisi altında kaldığı mitolojik öyküler, romanlar, şiirler hatta siyasi olaylar dahi yazılan eserlerin karakterini yansıtmaktadır.

Öncelikle müzisyenin amacı yazılan eserlerin öyküsünü anlamak hatta neyi betimlediğini kavramak olmalıdır. Örneğin: Reinecke 1882 yılında yazdığı "Undine Op.167" (Deniz Kızı) adlı flüt-piyano sonatını Friedrich de la Motte Fouqué ${ }^{15}$ 'un (1777-1843) romanından esinlenerek yazmıştır. Fouqué, eserlerinde İskandinav saganlarından ve mitlerinden yararlanmıştır. Undine, sıcacık, romantik bir masalı ruhun ıstırapları ve doğaüstünün gizemiyle fantastiğe yaklaştıran sıra dışı bir yapıttır. Fouqué, acıya mahkûm bir var oluşu tatmak uğruna ölümsüzlüğü arzulayan ve ruhun bedelini acı çekerek ödeyen bir efsaneyi anlatır. Bu bağlamda, eseri yorumlarken içinde bulunduğumuz hikâyenin özünde var olan gerçeği

\footnotetext{
${ }^{8}$ Fransız flütist ve flüt öğretmeni.

${ }^{9}$ Fransız flütist, besteci ve şef, modern Fransız flüt okulu kurucusu.

${ }^{10}$ Amerikalı yazar ve flütist.

11 İngiliz editör, yazar, flütist.

${ }^{12}$ Alman Barok dönem bestecisi.

${ }^{13}$ Avusturyalı Klasik dönem bestecisi.

* Barok çağ sonu (1750'ler) ile Romantik çağ başları (1830'lar) arasında yaşayan Mozart, Haydn, Beethoven gibi besteciler zamanındaki müziğe verilen ad (Aktüze, 2003:296).

${ }^{14}$ Alman Romantik dönem piyanist, şef ve besteci.

${ }^{* *}$ Müzik tarihinde 1790 (ya da 1815) yıllarında geç-klasisizm sonu ile 1910'a, empresyonizm (izlenimcilik) ve eskpresyonizm başlangıcına kadar süren, duyguya, coşkulu olmaya ve hayal gücüne çok önem verilen, Beethoven ve Schubert gibi bestecilerin geçiş sürecini başlattıkları, Mendelssohn, Schumann, Brahms, Wagner, Berlioz, Chopin, Liszt gibi bestecilerle devam eden, şiir ve resim gibi güzel sanatların diğer dalları ile folklorla yakın ilişkisi olan sanat akımı (Aktüze,2003:489).

${ }^{15}$ Alman Romantik dönem roman ve oyun yazarı.
} 
kavrayıp uygulayacağımız ses rengi ve dolayısıyla sesin ayrılmaz bir parçası olan vibratoyu da, hikâyenin ruhumuzda bıraktığı etkileri içinde oluşturmalıyız. Bu öğretiler flütistin kişisel süzgecinden geçerek tümüyle kendi ruhunu yansıtmasını sağlar ve kendinden emin, daha kültürlü bir performansın kapılarını açar. Kültürel birikimin varlığı asla red edilmemeli ve sürekli geliştirilmelidir. Çünkü bu ruhumuzu besleyen önemli bir etkendir.

Flüt edebiyatının en önemli ve sıklıkla çalınan eserlerini Fransız besteciler yazmıştır. Bu nedenle Fransız Flüt Okulu iyi öğrenilmeli ve onların müzikal anlayışları incelenmelidir. Ayrıca bu bağlamda, Fransız toplumunun sosyal-kültürel birikimlerini algılamak konusunda da hassasiyet gösterilmelidir.

İşitsel anlamda da dinlediğimiz müziklerin kişi üzerindeki etkisi önemlidir. Ünlü İrlandalı flütist James Galway'in "Flüt" (Flute) adlı kitabında, öğrencilere Jascha Heifetz'16 (1901-1987) ve Maria Callas ${ }^{17}$ 'ın (1923-1977) müzikal performanslarının dinlenmesi önerilmiştir (Galway,1990:105). Aslında bu öneri teknik anlamda Heifetz ve Callas'ın vibratolarının örnek alınması doğrultusunda olsa bile, temelde bu iki sanatçının kültürel ve entelektüel birikimini vurgulamaktadır. Heifetz'in vibratosu çok yoğundur. Callas'ın vibratosu ise yavaş ve nettir. Her iki sanatçının da vibratosu stil olarak birbirinden farklı olmasına rağmen, müziğe içsellikle ve doğal bir şekilde yansımıştır. Aslında doğal yetenekleri olan bir müzisyenin vibratoyu kolaylıkla elde edebileceği konusundaki hassasiyet de çok önemlidir. Ancak çok nadir olarak gözlenebilen bu doğal yetenek, vibrato çalışmaları ile desteklendiğinde birçok flütisti ortak bir anlayış çevresinde buluşturma imkânı verir.

Özellikle oda müziği eserlerinde ortak bir vibrato anlayışı ve onun kültürel boyuta taşınması, müzisyenlerin stil, yorum ve teknik uyum içinde çalışmasını ve eserin ahenginin gelişmesini sağlamıştır. Uzun yıllar birlikte çalan müzisyenlerin doğal olarak ortaya koydukları öz uyum ve müzikal yorum, grubun kültürel birikimlerinin bir yansıması olarak ortaya çıkar. Ancak günümüzdeki yüksek eğitim standartları çerçevesinde yetişen müzisyenler, gerek teknik anlamda gerekse edindikleri öğretiler doğrultusunda ortak anlayışa daha çabuk ulaşmaktadırlar. Bu yaklaşım orkestraların yorumlarını ve kimliklerini belirleyen ana ögelerden biri haline gelmiştir. Örneğin; Eğer bir flütist, orkestra içerisinde solo bir pasaj çalıyorsa genelde bu pasaj orkestra şefinin tanımladığı ayrıntılar üzerinde gelişir ve flütistin tanımlanan bu ayrıntılar üzerinde yorum (vibrato) yapması söz konusudur. Fakat tutti pasajlarda özellikle tahta üflemeli çalgıların tınısal bütünlüğünün ve entonasyon anlayışının korunabilmesi için vibratosuz çalması daha uygun olacaktır.

\section{Müzikal ve Teknik Anlamda Flüt Vibratosu}

Teknik anlamda vibrato, hava basıncının arttırılarak ve azaltılarak sesin içerisinde tizleşip-pesleşmeye neden olan dalgalara verilen addır. Yaklaşık 300 yıldır flüt vibratonun elde edilmesiyle ilgili devam eden tartışmalar teknik ve müzikal anlamda halen günümüzde de devam etmektedir. Quantz'ın "Flüt Çalmayı Öğrenme Üzerine Deneme" (Versuch Einer Anweisung Die Flöte Traversiere Zu Spielen) kitabında, Adagio yorumlama konusunda vibratodan yani flattement'ten açıkça bahsedilmiştir. Bu bölümde re minör, do minör, fa minör ve re diyez Majör tonlarında yazıımış olan Adagio bölümleri melankolik ve içsel tonlar olarak ifade etmiştir. Bu tonlara özel şık ve zarif flattementler yapılması gerektiğini vurgulamıştır. Örneğin; sol minör tonunda bir Adagio çalarken kederli bir anlayışla yorumlamamız gerektiği gelenekselleşmiştir. Vibrato anlayışının gelişimi ile birlikte bu geleneksel anlayışa çağdaş bir yaklaşım göstermek bir zorunluluk haline gelmiştir. Quantz, ağır bölümlerdeki uzun notaları hafif bir dil vuruşu ile başlayıp yumuşak bir crescendo içerisinde şık vibrato (flattement) yapılması gerektiğinden bahsetmiştir. Buradaki şıklık, hafiflik; kesinlikle flütistin entelektüel düzeyi ile ilgili olmasının yanı sıra, aslında bir anlamda da vibratonun hızını tarif etmektedir. 1900'lü yılların başında Fransa'da üflemeli çalgı çalanlar vibrato kullanarak çalmaya karşı çıkıyorlardı. 1906-1914 yılları arasında vibrato ile çalanların genel anlamda küçümsenmesi ve kınanmasına rağmen o dönemdeki flütün yapısından dolayı ortaya çıkan entonasyon problemlerini bertaraf edebilmek ve sesin kalitesini artırmak için flütistler tarafından gizlice tercih edilen bir konuma gelmişti. Çünkü dönemin genç flütçüleri vibratoyu acımasızlık, suçluluk, isterik ve koleradan daha kötü bir hastalık olarak tanımlıyorlardı. Dönemin en önemli flütistlerinden Marcel Moyse (1889-1984), bu yıllarda "Cesaretli bir şekilde neden kimse vibrato yapmasın veya yapıyorsa neden gizlice yapıyor" soruları ile vibratonun müzikaliteyi geliştirdiği dolayısıyla müzikal yoruma melodik anlam kattığı ve ses kalitesine olumlu etkiler sağladığı gerçeği ile

\footnotetext{
${ }^{16}$ Litvanya'lı ünlü Rus keman virtüözü.

${ }^{17}$ Yunan-Amerikan soprano, XX. Yüzyılın en tanınmış opera şarkıcısı.

* İtalyanca tutti: Tüm, hepsi. Orkestra ya da koroda tüm müzikçilerin birlikte katılımıyla seslendirmesi (Aktüze,2003:620).
} 
yüz yüze kalınmıştır. Taffanel'in önderliğinde kurulan ve Boehm Sistem flütün Paris Konservatuvarı'nda kullanılmaya başlanmasıyla birlikte yeni bir anlayış kazanan flüt eğitimi vibratonun kullanılması anlamında da yeniliklerin ortaya çıkmasına neden olmuştur. Ancak vibratodan sesteki dalgalanma olarak değil daha fazla sesteki ifadenin güçlendirilmesi olarak bahsetmişlerdir. Günümüzde hala vibrato ve ifadeli çalmak kelimeleri güncelliğini korumakta ve bununla beraber nasıl, nerede, ne zaman ve ne kadar uygulanması gerektiği konusundaki tartışmalar devam etmektedir. Aslında bu durum tamamen flütçülerin müziğe olan yatkınlıkları, yetenekleri, ruhsal algıları ve olgunlaşması ile paralellik gösterir, bir anlamda da sesin felsefi boyut kazanması denebilir.

Vibrato müziği tasvir etmek için kullanılan birincil öğedir. Örneğin; Thomas Mann ${ }^{18}{ }^{\prime}$ ın (1875-1955) Büyülü Dağ adlı romanında bir paltonun düğmesi nasıl sayfalarca tasvir ediliyorsa. Vibrato da müzikal tasvire bir o kadar incelikli ve rafine bir anlayış katar. Moyse'un 1900'lerin başında söylediği gibi "Gelecekte flütçülerin kalitesini onların vibrato anlayışı belirleyecektir." cümlesi flütçüler için vibratonun günümüzde ne kadar önemli olduğunu vurgulamaktadır.

Gilbert, Fransız flütist Rene Le Roy'un (1898-1985) etkisi ile kurduğu İngiliz flüt okulunda, vibratonun içsel bir yetenek olmasının dışında teknik anlamda da çalışılarak geliştirilebileceğini açık bir şekilde ifade etmiştir. Bununla beraber, müziğin ruhsal akışıyla birleştirilmesi gerektiğini, psikolojik ve fiziksel faktörlerin de çok önemli olduğunu vurgulamıştır. Gilbert'e göre, vibrato çalışırken nefes borusu olabildiğince açık olmalıdır. Böylece hava rahat bir şekilde flütün üfleme deliğine ulaşır. Bu esnada havanın hızı ve vibratonun şiddetinin boyutu karın kasları ile kontrol edilmelidir (Floyd,1990:90). Bu durum karın kaslarımızın fiziksel olarak kontrol edilebilmesiyle ve gücüyle doğrudan ilişkili olduğunu ortaya koymaktadır. Bu yaklaşım flütçüye vibratonun hızını kolaylıkla kontrol edebilmesini ve müzik üzerindeki etkisini arttırmasını sağlayacaktır. Vibratonun hızının fiziksel olarak kontrol edilebilir olması flütçüye engin bir yorum gücü kazandırır. Örneğin; bir bölüm başlığı tutkulu ve ateşli (con fuoco et appasionata) ve forte nüansla başlıyorsa bu vibratonun hızlı ve derin kullanılmasının gerekliliğini gösterir.

\section{Vibrato Çalışma Yöntemleri}

Nasıl günlük konuşmada sürekli sesimizi titretmiyorsak veya şarkı söylediğimizde her sesi ve her heceyi titretmiyorsak, yorum esnasında da her sese aynı titreşimlerle vibrato yaparak çalınmamalıdır. Bu nedenle, vibrato çalışmalarına başlamadan önce doğal bir flüt sesi elde edilmelidir. Doğal flüt sesinin açıımı doğru entonasyonlu ses kontrolünü gerektirmektedir. Elde edilmesi gereken bu doğru entonasyonlu ses, flütistin başlangıç çalışmalarında ağızlıktan elde ettiği sesin doğruluğuyla paralellik göstermektedir. Bu nedenle en çok dikkat edilmesi gereken faktör ağızlığın alt dudakta doğru konumlandırıması ve açılandırımasıdır. Ağızıık deliğinin dörtte üçünün açık bırakılması gerekmektedir. Ayrıca yüz kaslarında elde edilmesi gereken esneklik de doğru sesin elde edilmesinde önemli bir ayrıntıdır. "Flütün bir zamanlar vibratosuz çalındığını hatırlayın. Dalga, düz ve temiz bir ses elde ettikten sonra eklenir" (Wye,1983:19-24).

Çalışmaya başlamadan önce temelde uyguladığımız nefes alma ve verme egzersizlerini doğru bir şekilde yapılması ve elde edilmesi zorunluluğu göz ardı edilmemelidir. Aksi takdirde nefes kapasitesi yeterince gelişmemiş bir flütist bu çalışmaları yaparken sürekli nefes problemi yaşayacaktır. Nefes problemi var olan bir flütist, vibrato çalışmayı aşağıda önerilen karın kasları kullanımı ile değil boğazıyla kontrol etmeye çalışacaktır. Bu da ortaya çıkan ses dalgalarının daralmasına, tizleşmeye ve kontrolsüz bir şekilde yapılmasına neden olacaktır. Vibrato karın kasları ile elde edilmelidir. Ses telleri, sinüs boşlukları, boğaz ve omuzlar sese etki etmemelidir. Her şeyden önce birinci adım doğru nefes almak, ikinci adım doğru nefes vermektir. Üçüncü adım ise karın kaslarının farkındalığını artırmak ve etkin bir şekilde geliştirmek için temel nefes egzersizlerini düzenli bir şekilde yapmaktır.

Wye'a göre, öncelikle vibratosuz birkaç nota çalın. İç çeker gibi alt karın kaslarını hissedin ve bu kasları kullanın. Eğer istem dışı bir vibrato elde edilmesi söz konusu olursa bunu yapmamaya çalışın. Sesi tamamen düz bir şekilde elde ettikten sonra flütü sadece, sol elinizle taşıyarak kalın sol notasını çalın ve diğer elinizi karın kaslarınızın üzerine koyun. Hava basıncının yükselip alçalmasını başlatabilmek için sağ elinizi karın kaslarınızın üzerine koyun ve ritmik bir şekilde içeri-dışarı basınç uygulayıp bırakın. Böylece elinizin uyguladığı basınç ile hava basıncı yükselip alçalacaktır. Illk olarak bu yöntemle saniyede 2 ve 3 dalgalanma elde etmeye çalışın. Bunu sessizce "ha-ha-ha" hecesini söyletmeye benzetebiliriz (Wye,1983:19-24).

\footnotetext{
${ }^{18}$ Alman romancı ve kısa hikâye yazarı.
} 
Toff'a göre vibrato, sesin içerisinde ölçülebilir bir dalgalanmadır veya hava basıncı yardımı ile tonda bir efekttir. Bu efekt, nabız veya dalgalanma etkisidir. Ancak işittiğimizin tam olarak ne olduğunu tanımlamak kolay değildir. Vibrato tonun içerisinde yer alır ve tondan ayrıştııılmamalıdır. 3 temel vibrato modeli vardır; 1-Ses aralığı (pitch) 2-Yoğunluk, Şiddet (intensity), 3-Ses rengi, tını (timbre).

1. Ses aralığı (pitch) vibratosu; ses yukarı-aşağı dalgalanır örneğin; ana sesimiz la-440 ise dalgalanma 438 ve 442 frekansları arasında gerçekleşir. Bir anlamda sesin tizleşip-pesleşmesidir. Bunu yaparken ses önce tizleşir sonra pesleşir.

2. Yoğunluk (intensity) vibratosu; çaldığımız notanın gücünün dalgalanması ile elde edilir. Bir anlamda sesin Forte-Piano dinamikleri arasında gidip-gelmesidir.

3. Ses rengi, tını (timbre) vibratosu; ses aralığı (pitch) vibratosu ve yoğunluk (intensity) vibratosunun birleşimi ile oluşmaktadır. Bir sesin gücünde (nüans) değişiklikler yapıldığı zaman 0 sesin içinde var olan üst armoniklerin sırası değişir ve bu üst armoniklerin meydana getirdiği değişiklikler tınısal vibratonun oluşmasına neden olur (Toff, 1985:106).

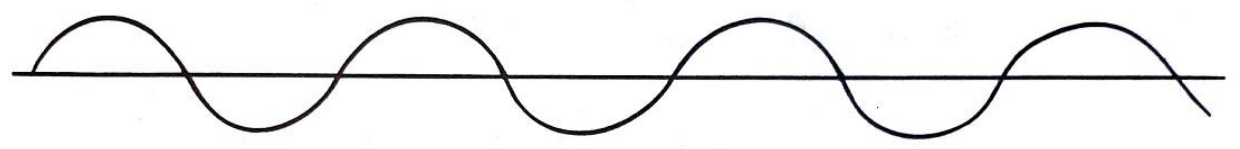

Şekil 1.

Şekil 1'deki grafikte, ana ses düz çizgi, dalgalar da ana sesin altında (pesleşme) ve üstünde (tizleşme) olarak gösterilmiştir.

En temel vibrato çalışma yöntemi metronom ile vibratonun hızını kontrol ederek çalışmaktır. İleri safhalarda bu elde ettiğimiz farklı metronomlardaki farkıı hızlar müziğin içine uygulanacaktır. Ancak bu aşamaya gelindiğinde vibrato sayılabilir olmamalıdır.

Bu çalışma Ha-Ha- Ha, Hu-Hu-Hu, Ho-Ho-Ho gibi farklı heceler kullanarak vibrato üzerinde çeşitlilik yaratabiliriz. Bu çeşitli heceleri her oktavda farklı şekillerde kullandığımızda alt seslerde sıkışmamayı üst seslerde ise genişliğinin daralmasını önlediğini görürüz. Ancak bu çalışmalar mekanik ve sayılabilir olmamalıdır. Günümüzde çok farklı çalışma yöntemleri yazılmış ve uygulanmaktadır. Ancak en çağdaş ve kullanılabilir yöntem Trevor Wye (1935- ) tarafından yayınlanan "Entonasyon ve Vibrato Çalışma Kitabı" (Practice Book fort he Flute: Intonation and Vibrato) adlı kitapta ele alınmıştır (Wye,1983:19-24).

\subsection{Vibrato Alıştırmaları}

Alıştırmaları yaparken sürekli esnemeyi düşünmek elde edilen ses kalitesini yükseltir ve dolayısıyla ikinci ve üçüncü oktavdaki seslerin sıkışıklığını önleyecektir. Ayrıca bu durum, akciğerlerdeki havanın zorlanmadan enstrümana ulaşmasını sağlayacak ve sese de sıcaklık katacaktır. Bu alıştırmaları farklı oktavlarda ve tonlarda çalışmak, flütiste her tonda farklı renkler elde etmeyi sunar, ifade gücünü arttırır, ayrıca tonalite anlayışının gelişmesine de katkıda bulunur. Bir anlamda da kişisel ifade gücünü arttııı ve çeşitlendirir.

\subsubsection{Genel Vibrato Çalışması}

Sol majör gamı üzerinde örneklenen bu çalışmada, her notada 8 ses dalgası elde etmeye çalışılmalıdır. 60 metronomdan başlayarak 90 metronoma kadar yükseltmeyi deneyin. Farklı dinamiklerle, farklı metronomlarla, 2'den 8'e kadar hızlandırabileceğimiz bu dalgalar, flütistin vibratosunu geliştirmesini ve vibratonun hızını kontrol edebilmesini sağlayacaktır. Karın kaslarıyla başlayan dalgalanmalar hızlandıkça ses tellerinin de doğal olarak devreye girmesi ile vibrato daha estetik, olgun ve rafine hale gelecektir. 


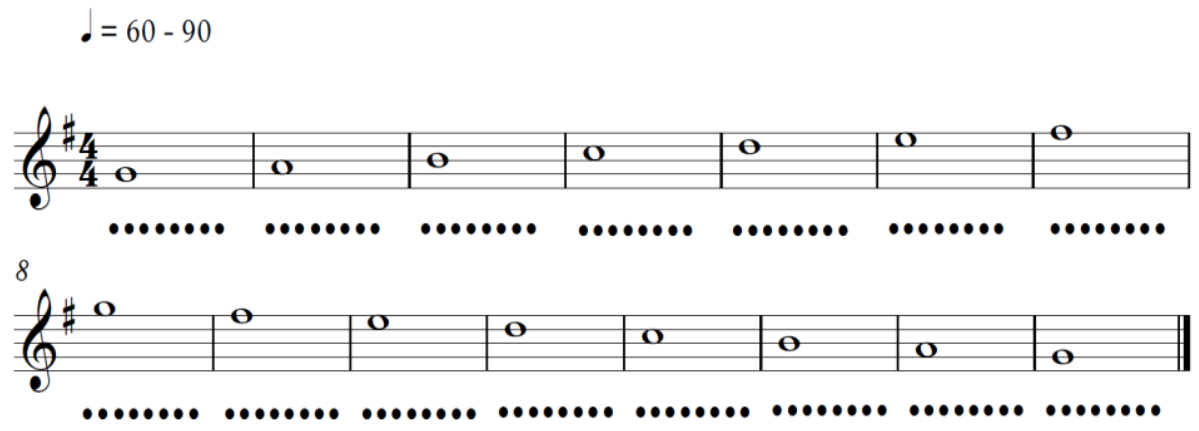

Şekil 2.

Şekil 2'de notaların altındaki noktalar ses dalgalarının sayısını belirtmektedir.

\subsection{2. Çan Sesi Vibratosu}

Flüt en kolay ses kapatabilme (diminuendo) özelliğine sahip olan enstrümandır. Bu avantajı vibrato ile birleştirdiğimizde eserlerin birçok yerinde büyülü efektler elde edebiliriz. Ses kapatma egzersizleri ile ilgili farklı çalışma yöntemleri üretilmiştir. Bu çalışmalar kapatılan sesin sonunda ortaya çıkan peslik (entonasyon) probleminin önüne geçmek için önerilmiştir. Dolayısıyla çan vibratosu çalışabilmek ve geliştirebilmek için ses kapatma egzersizlerinin $\mathrm{t}$ am anlamıyla doğru uygulanması gerekmektedir. Bu çalışma farklı uzunluktaki notalar üzerinde vibrato ile birleştirildiğinde çalınan eserin estetik boyutu gelişir.

Çalışmaya geçmeden önce alıştırma 1'deki genel vibrato anlayışının tamamen kavranması ve uygulanması gerekmektedir. Bu nedenle bir temel oluşturmadan asla uygulanmamalıdır.

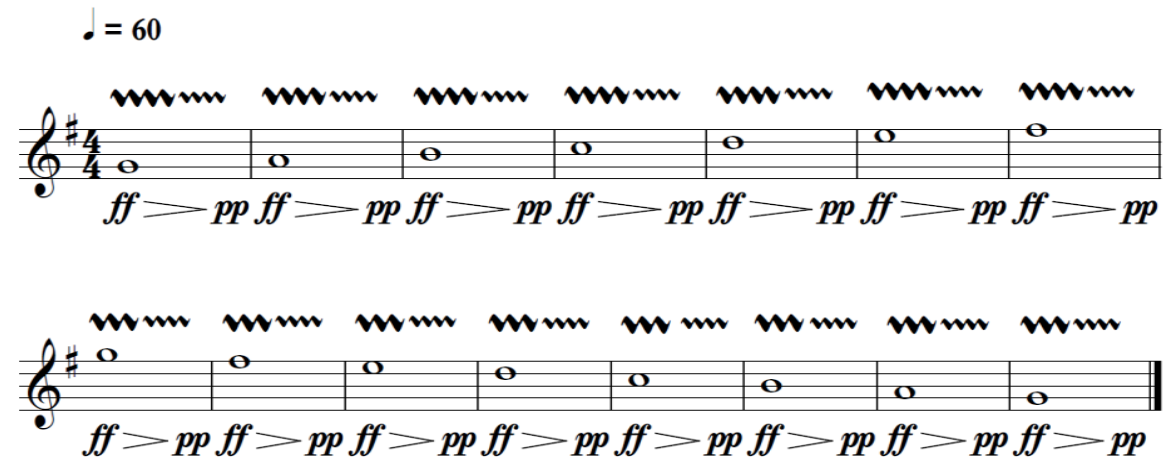

Şekil 3.

Şekil 3'de çalışmada notaya çok hızlı vibrato ile başlayıp tempo içerisinde vibratoyu giderek yavaşlatarak bir çan algısı geliştirilebilir. Bu farklı tonlar ve oktavlarda yapılabilir. Ayrıca 3/4, 2/4, 4'lük ve 8'lik notalar üzerinde de çalışılabilir.

\subsubsection{Girdap Vibratosu}

Ses kapatma egzersizinin (diminuendo) aksine sesi açarak (crescendo) bir nevi girdap gibi duyulan bu çalışmada vibratoya çok yavaş başlanır ve giderek hızı arttıııır. Bu yöntem hem sesin gücünü arttırmamızı sağlar hem de sesin çiğliğini ortadan kaldırır. Özellikle 3. oktavda uzun notalar üzerinde büyük etki yaratır. 


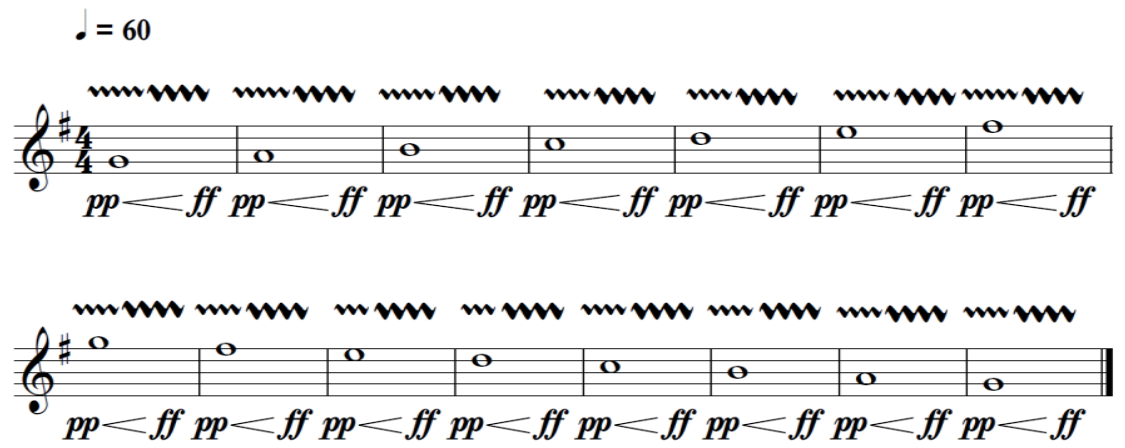

Şekil 4.

\subsubsection{Melodik Pasajlar Üzerinde Vibrato Çalışma}

Marcel Moyse "24 Küçük Melodik Etüt" (24 Petites Etudes Melodiques) kitabında 1 numaralı etüt Do Majör tonunda yazılmıştır. Armonik olarak I-V-I mükemmel kadans içerisinde devinim göstermektedir. İkişer ölçülük cümleciklerden oluşan bu çalışma, tamamında sekizer ölçülük iki ana müzik cümlesinden oluşmaktadır. İlk cümlecik, pianissimo nüansla, piano nüans arasında gerçekleşir. İkinci cümlecik, piano nüans (p) ile mezzo forte (mf) arasında devam eder ve son iki cümlecik müziği forte nüansa ulaştırır. Bu örnek içerisinde vibratonun hızının kontrol edilerek bir anlamda da piano nüanslarda az, forte nüansa gelindiğinde ise daha yoğun vibrato yaparak, müziğin nabzını tutmak mümkündür. Bu çalışma farklı tonlarda çalışılarak etkisi genişletilebilir. Aşağıdaki örnekte bu çalışma içerisinde yaklaşık olarak elde edilmesi ön görülen ses dalgaları detaylı bir şekilde incelenebilir.

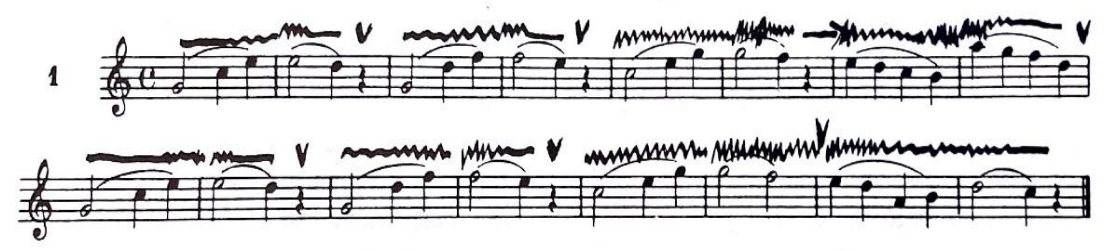

Şekil 5.

\section{SONUÇ}

Tüm canlılarda, nabız psikolojik etkenlere göre değişkenlik göstermektedir. Vibrato da, eserin yorumuna sanatsal boyut kazandırılması açısından psikolojik bir etken olarak müziğin ruhunu estetik bir anlayışla doğrudan etkiler.

Evrende var olan tüm titreşimler, insanoğlu tarafından dolaylı veya dolaysız yoldan algılanmaktadır. Dolaylı yolla öğrendiklerimiz bizlerin bilgi birikimini geliştirir, dolaysız yoldan öğrendiklerimiz ise, farkında olmadan oluşturduğumuz refleksler olarak karşımıza çıkar. Bu bağlamda bir sanatçı için en önemli unsur, farkındalığı arttırıp bunları sanatsal boyuta taşımak olmalıdır.

Yaylı çalgılarda 800 yıldır var olan vibrato anlayışı, nefesli çalgıların anatomik yapılarının geç gelişmesi nedeniyle ancak 1900 'lü yılların başlarında konuşulmaya başlanmıştır. Nefesli çalgılardan çok daha ilerde olan bu anlayış, teknik olarak yaylı çalgılar örnek alınarak geliştirilmelidir. Şarkı söyleme tekniğiyle çalınan flüt söz konusu olduğunda, müziğin teknik boyutunda yaylı çalgılar örnek alınmalı 
ancak şarkılama yeteneğine sahip olan flütün şan tekniği ile çalınması gerekir. Dolayısıyla ortaya çıkan sonuç bir flütist için hayati önem taşımaktadır. Özellikle Fransız Flüt Okulu'nun desteklediği bu görüş tüm dünyada kabul görmüş fakat sonu gelmez bir şekilde bu konu üzerindeki bilimsel araştırmalar devam etmektedir.

Günümüz flüt eserlerinde dört forte (ffff) ve dört piano ( $p p p p)$ nüans aralığı sıklıkla kullanılmaktadır. Vibrato da tonun bir parçası olduğu için bu dinamik aralıklara uygun bir şekilde bütünlük sağlamalıdır. Modern flütün sağladığı olanaklar sınır tanımaz bir boyuta gelmiştir. XX. yüzyılda vibrato kullanımı evrenselleşmiştir.

İstemsiz olarak kullanılan kas grupları çalgıcının sıkışmasına neden olur. Bu nedenle öğrendiklerimizle ve duyduklarımızla sınırlı kalmayıp öncelikle insanın anatomik yapısını tanımak ve kas gruplarını incelemek konusunda duyarlıık sahibi olmak gereklidir. Bu bağlamda yanlış vibrato kullanımı söz konusu olduğunda fark edilmeyen problemler ve kas hastalıkları ile karşılaşııı. Bu problemler günümüz stüdyolarında çok hassas mikrofonlarla yapılan kayıtlara gürültü olarak yansır. Bu gürültüleri teknoloji dahi kayıt içerisinden temizleyememektedir. Ayrıca konser salonlarında ön sırada oturan dinleyiciler üzerinde huzursuz bir etki bırakır ve performans boyunca bu huzursuzluk konsantrasyon bozukluklarına neden olur. Vibrato hakkında devam eden uygulamalar ve teorik bilgiler gelişimine devam edecektir. Bu noktada önemli olan farkındalığın arttırılıp evrensel bilgilere ulaşılmasıdır.

Sonuç olarak, XX. yüzyıl müziğinde besteciler vibratoyu kontrol edilebilir bir etken olarak kabul ettikleri için, notaların üzerine vibratonun nasıl kullanılacağı konusunda işaretler kullanarak taleplerini ortaya koymuşlardır. Vibratonun müzik üzerindeki etkisi tartışılmazdır. Bu nedenle teknik, müzikal ve kültürel boyutta ele alınması zorunluluk haline gelmiştir.

\section{KAYNAKLAR}

1. Aktüze, İ. (2003). Müziği Anlamak, Ansiklopedik Müzik Sözlüğü, İstanbul: Pan Yayıncılık.

2. Ersöz, B. (2014). Flüt Vibratosu, Sanatta Yeterlilik Tezi, İstanbul: T.C. İstanbul Üniversitesi Devlet Konservatuvarı, Sosyal Bilimler Enstitüsü, Müzik Anasanat Dalı, Üflemeli ve Vurmalı Çalgılar Sanat Dalı.

3. Galway, J. (1990). Flute, London: Kahn\&Averill, 9 Harrington Road, , SW7 3ES UK.

4. Gartner, J. (1981). The Vibrato of the Flutist, Germany: Gustav Bosse Verlag Regensburg.

5. Floyd, S. A. (1990). The Gilbert Legacy: Methods, Exercises and Techniques, US:3743 Beaver Ridge Circle Cedar Falls, lowa 50613

6. Morris, G. (1991). Flute Technique, New York: Oxford University Press.

7. Quantz, J. J. (1966). On Playing The Flute, London UK: Faber and Faber Limited.

8. Toff, N. (1996), The Flute Book, New York: Oxford University Press.

9. Wye, T. (1983), The Practice Book, UK:.Intonation and Vibrato, Novello \& Company Limited, Brough Green, Sevenoaks, Kent. 